\title{
Control of Moldy-Core Decay in Apple Fruits by $\beta$-Aminobutyric Acids and Potassium Phosphites
}

\author{
M. Reuveni and D. Sheglov, Golan Research Institute, University of Haifa, P.O. Box 97, Katzrin 12900, Israel; and \\ Y. Cohen, Faculty of Life Sciences, Bar-Ilan University, Ramat-Gan Israel
}

\begin{abstract}
Reuveni, M., Sheglov, D., and Cohen, Y. 2003. Control of moldy-core decay in apple fruits by $\beta$-aminobutyric acids and potassium phosphites. Plant Dis. 87:933-936.

Alternaria alternata is the predominant fungal pathogen responsible for moldy-core decay in the 'Red Delicious' apple fruits. The failure of registered fungicides to control the disease necessitated the search for alternative methods. Here we report that DL- $\beta$-aminobutyric acids (BABA) and potassium phosphite are capable of controlling moldy-core in apple fruits in the laboratory and the field. Laboratory tests involving inoculation of wounded mature fruits revealed that decay by A. alternata was 40 to $58 \%$ inhibited by $50 \mu \mathrm{g} / \mathrm{ml}$ and completely inhibited by $500 \mu \mathrm{g} / \mathrm{ml}$ of potassium phosphite. DL-BABA, $R$-BABA, and $S$-BABA at a concentration of $500 \mu \mathrm{g} / \mathrm{ml}$ inhibited decay formation by 82 to $90 \%$. Potassium phosphite, BABA, and S-BABA inhibited decay formation even when applied 6 to $48 \mathrm{~h}$ postinoculation. In vitro tests indicated that BABA compounds did not affect conidial germination or mycelial growth, whereas potassium phosphite partially inhibited both developmental stages of the fungus. Results suggest that BABA inhibits fruit decay development indirectly, probably by inducing resistance in the host tissue, whereas potassium phosphite may act directly against the fungus. A preliminary field trial in a commercial apple orchard showed that three foliar applications of BABA or potassium phosphite, starting from the beginning of bloom until petal fall, reduced the number of fruits infected with moldy-core by 40 and $60 \%$, respectively, relative to fruits from nontreated control trees. Results suggest that potassium phosphite and BABA could provide adequate control of moldy-core disease in apple.
\end{abstract}

Additional keywords: disease control, induced resistance, Malus sylvestris (L.) Mill. var. domestica (Borkh.) Mansf.

Alternaria alternata is the predominant fungal pathogen responsible for moldycore in apple cv. Red Delicious (2). Spores presumably infect young fruits through the open calyx tube, and mycelia reach the seed and carpel wall during fruit development and storage (14). Moldy-core is characterized by the growth of the mycelia within the locules, with or without penetration into the mesoderm. The disease may become invasive and lead to a slow, dry rot confined to the flesh immediately surrounding the core $(10,18)$. External symptoms are rare, although infected fruits may color and drop prematurely $(10,18)$. Conditions of high relative humidity, mild temperatures, and tissue susceptibility are important factors that affect natural infection in orchards. Once inside the fruit, the fungus is protected from contact fungicides, and conditions for its continued growth are excellent.

In recent years, levels of moldy-core in 'Red Delicious' have caused significant

Corresponding author: M. Reuveni

E-mail: mreuveni@research.ahifa.ac.il

Accepted for publication 19 March 2003.

Publication no. D-2003-0528-01R

(C) 2003 The American Phytopathological Society losses in Israel. The incidence of fruits infected with moldy-core, according to samples taken from a packing house in northern Israel was $15,8,7,5$, and 4 to $5 \%$ in 1997, 1998, 1999, 2000, and 2001, respectively (M. Reuveni, unpublished). In general, when more than $9 \%$ of the fruits are infected they can only be sold at a very low price. 'Red Delicious' constitutes approximately one-third of the total number of apple trees planted in Israel. Therefore, moldy-core is a major factor reducing apple fruit quality with an economically important impact.

Attempts to control Alternaria spp. and moldy-core with foliar applications of fungicides such as benomyl, captan, dodine, iprodione, mancozeb, or combinations of these fungicides have been unsuccessful $(1,9,10)$. These failures indicate the need for alternative methods. The introduction of the plant defense activator DL- $\beta$ aminobutyric acids (BABA) by Cohen $(5,6)$ provided a new option for chemical management of plant diseases based on the induction of host resistance. Previous studies by Y. R. Cohen and other researchers, demonstrated the effectiveness of BABA in inducing local and systemic protection against a wide range of fungal plant pathogens belonging to different classes, including Alternaria brassicicola in broccoli and
A. solani in potato $(6,8)$. The inhibitory effects of phosphites against Oomycetes (7) and other fungal plant pathogens have been demonstrated (11,12). They act through direct effects on the pathogen and indirect effects on the host (11).

The objective of the present study was to evaluate the inhibitory effect of BABA and potassium phosphite on decay formation in apple fruit caused by $A$. alternata in the laboratory and nature. In vitro studies were also conducted. The data suggest good efficacy of the compounds tested in controlling moldy-core in apple fruits.

\section{MATERIALS AND METHODS}

Chemicals. BABA (DL-3-amino- $n$ butanoic acid, DL- $\beta$-aminobutyric acid) was purchased from Sigma Chemical Co., St. Louis, MO. We tested 3 BABA compounds: the two enantiomers, $R$ and $S$, and the DL- racemate. The $25 \mathrm{WP}$ (wettable powder) formulation of $\mathrm{BABA}$ used for field experiments was obtained from Makhteshim-Agan, Beer Sheva, Israel. The $R$ and $S$ enantiomers of BABA were kindly supplied by Sandoz Agro (Basel, Switzerland). Potassium phosphite, a solution of mono- and di-potassium phosphonate ions $\left(\mathrm{KH}_{2} \mathrm{PO}_{3}\right.$ and $\mathrm{K}_{2} \mathrm{HPO}_{3}$, pH 4.5) was supplied by Fertilizers and Chemicals, Ltd. Haifa, Israel. All concentrations in laboratory experiments are presented as $\mu \mathrm{g} / \mathrm{ml}$ of active ingredient (a.i.). The efficacy of BABA and potassium phosphite in controlling moldy-core and A. alternata in apple fruits in the orchard was compared to that of the systemic sterol inhibitor fungicide difenoconazole (Score, 250 EC, Syngenta, Basel, Switzerland) (17).

Fungal isolate and inoculation procedure. A. alternata was isolated from 'Star King' apple fruits infected with moldy-core disease. Fruits were disinfected with $90 \%$ ethanol, and small pieces ( 1 to $2 \mathrm{~mm}$ ) of the mesoderm tissue external to the core region showing moldy-core symptoms were removed and incubated on potato dextrose agar (PDA) at $25^{\circ} \mathrm{C}$. Single-spore cultures were maintained on PDA for 10 to 12 days until conidia were produced. For inoculation, mature 'Star King' fruits were brought from the orchard, washed with water, blotted dry with a paper towel, sprayed with $90 \%$ ethanol, and allowed to dry at room temperature. Conidia were harvested from cultures by adding a small amount of sterile distilled water to each dish and gently rubbing the sporulating 
mycelial mats with a bent glass rod. The spore concentration was adjusted with the aid of a hemacytometer to yield a suspension containing $5 \times 10^{5}$ spores $/ \mathrm{ml}$. Each fruit was pricked with a sterile pipet tip to a depth of $2 \mathrm{~mm}$ and inoculated by pipetting $15 \mu \mathrm{l}$ of conidial suspension into each wound. Following inoculation, fruits were placed on trays containing wet filter paper, covered with plastic bags to maintain high humidity, and held in a growth chamber $\left(25^{\circ} \mathrm{C}, 100\right.$ to $120 \mu \mathrm{E} \cdot \mathrm{m}^{-2} \cdot \mathrm{s}^{-1}, 16 \mathrm{~h}$ of light per day) for 10 days.

Experiments on detached fruits. To assess the effect of each compound on decay development in detached fruits, an aqueous solution of each compound was mixed with equal volume of conidial suspension to obtain the final concentration required for each compound. Inoculum concentration in mixtures was kept constant at $5 \times 10^{5}$ conidia/ml. The control conidial suspension was mixed with an equal amount of water. Each fruit was pricked at six sites to a depth of $2 \mathrm{~mm}$ with a sterile pipet tip. Each site was inoculated with $15 \mu \mathrm{l}$ of each mixture. Following inoculation, fruits were incubated in a moist chamber as described above and held at $25^{\circ} \mathrm{C}$ for 10 days. The diameter of the decayed area at each inoculation site was measured every 2 days. Three fruits were used for each concentration of each fungicide.

The postinoculation effect of a compound on decay development was examined in detached fruits as follows: fruits were treated as described above, pricked at six sites and each site was inoculated with $15 \mu$ l of suspension of $5 \times 10^{5}$ conidia per $\mathrm{ml}$. Following inoculation, fruits were incubated in a moist chamber as described above and held at $25^{\circ} \mathrm{C}$. At $0,6,24$, and 48 $\mathrm{h}$ postinoculation, each site was loaded with $25 \mu \mathrm{l}$ of $500 \mu \mathrm{g}$ a.i. $/ \mathrm{ml}$ of each compound. The inoculated control fruits were loaded with $25 \mu \mathrm{l}$ of water. Three fruits were used at each postinoculation treatment time. The diameter of the decayed area was measured every 2 days, but only data from day 10 are shown.

In vitro assays. The effects of $\mathrm{BABA}$ and phosphite compounds on germination of conidia of $A$. alternata were tested in vitro.

Conidial suspensions of $A$. alternata were kept in 1.5-ml tubes and mixed with aqueous solutions of each test compound to make final concentrations of $0,50,250$, and $500 \mu \mathrm{g}$ a.i./ml, while conidial concentration (approximately 50,000 per $\mathrm{ml}$ ) remained constant. Twenty microliters of the mixtures were pipetted onto depressions of microscope slides and incubated at $22^{\circ} \mathrm{C}$ for $20 \mathrm{~h}$ in the dark. The number of germinating conidia was counted under a microscope and percent germination was calculated.

The affects of BABA and phosphite compounds on mycelial growth of $A$. alternata were tested in vitro. Threemillimeter agar disks bearing A. alternata were taken from 14-day-old cultures on PDA and were placed on PDA in 9-cm petri dishes amended to make final concentrations of $0,10,50$, and $250 \mu \mathrm{g} / \mathrm{ml}$ of each compound. Cultures were incubated at $25^{\circ} \mathrm{C}$ in the dark and colony diameter was recorded every 2 days. Only data from the sixth day are presented. Three petri dishes containing three inoculum agar disks per dish were used for each treatment concen-

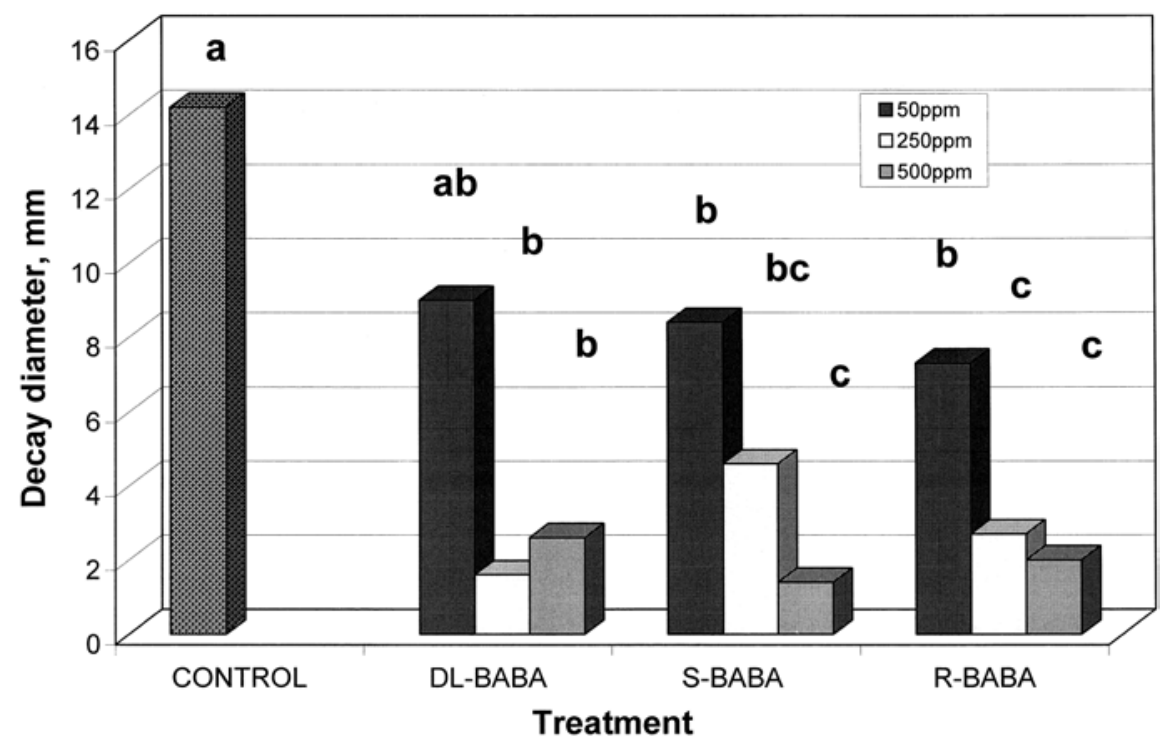

Fig. 1. Inhibition of decay caused by Alternaria alternata on postharvested apple fruits treated with BABA and $R$ - and $S$-enantiomers of BABA. Six sites on each fruit were treated with $15 \mu \mathrm{l}$ of an aqueous mixture of conidial suspension and the test compound. Fruits were incubated in a moist chamber at $25^{\circ} \mathrm{C}$ for 10 days. The mean decay diameter produced in each inoculation site on three fruits per each compound concentration is shown. Bars with different letters are significantly $(P<$ 0.05 ) different according to Waller-Duncan $k$-ratio $t$ test. tration, and experiments were conducted twice.

Field experiment. To expand our laboratory work, a single field experiment with 'Star King' was conducted in a commercial orchard in 2001 in the Golan Heights Region of Israel. Moldy-core has been prevalent in this orchard in previous years. Fertilization, irrigation, and other cultural practices were used as recommended to commercial growers by the Extension Service of the Ministry of Agriculture, Israel. The annual rainfall in this region during the winter (October to April) is 800 to 900 $\mathrm{mm}$, and the average midday relative humidity ( $\mathrm{RH})$ and temperature in summer are 35 to $40 \%$ and $30^{\circ} \mathrm{C}$, respectively. The sky is cloudless during most of the summer. Night temperatures fall occasionally to 14 to $20^{\circ} \mathrm{C}$ from the end of May until August, and dew may accumulate during some nights on the leaf surface. During the spring, moderate temperatures $\left(10\right.$ to $\left.25^{\circ} \mathrm{C}\right)$ and high humidity in this region favor infection by A. alternata.

Application of the compounds began at bloom stage. Sprays were applied to runoff (2,500 liters/ha) with a 100-liter gunsprayer $(1,400 \mathrm{kPa})$, at time intervals based on host phenology. Spacing between trees was $5 \times 3 \mathrm{~m}$ with a buffer row between treatments. Treatments were arranged in a randomized complete block design. Treatments were replicated five times in plots consisting of four trees each.

Difenoconazole $(0.01 \% \mathrm{wt} / \mathrm{vol})$, BABA $(0.2 \% \mathrm{wt} / \mathrm{vol})$, and potassium phosphite $(0.3 \% \mathrm{wt} / \mathrm{vol})$ were tested at El-Rom orchard on 'Star King' trees (18 years old, on MM.106 rootstock). Each compound was sprayed three times, starting on 1 April at $50 \%$ bloom, followed by applications on 5 April (full bloom), and 11 April (80 to $90 \%$ petal fall). Nontreated trees were used as controls.

At the end of the growing season, 20 fruits were arbitrarily collected from each replicate plot and brought to the laboratory. Each fruit was cut longitudinally into halves and a small part (approximately 2 $\mathrm{mm}$ ) of the mesoderm tissue, at a distance of approximately $2 \mathrm{~mm}$ outside the core region was aseptically removed from each half and plated on PDA. Dishes were incubated at $25^{\circ} \mathrm{C}$ in the dark for 8 to 10 days, and colonies and conidia of A. alternata were examined microscopically. The percentage of fruits colonized with A. alternata was determined. In addition, the incidence of fruits infected with moldy-core in the mesoderm outside the core region was visually determined at 25 July and at harvest on 10 September 2001.

Data analysis. Each laboratory experiment was conducted at least twice. Data from repeated experiments were combined for analysis when variance between experiments was homogeneous. All data were processed with the SAS GLM statistical software package (SAS Institute, Cary, 
$\mathrm{NC})$. The $\mathrm{EC}_{50}$ and $\mathrm{EC}_{90}$ values for inhibition of conidial germination or mycelial growth was calculated using probit analysis (SAS Institute). For the field experiment, analysis of variance (ANOVA) was applied to arcsine-transformed data. Waller-Duncan $k$-ratio $t$ test was applied to determine whether differences between treatments were significant.

\section{RESULTS}

Experiments on detached fruits. Fruit decay formation by A. alternata was inhibited by BABA (Fig. 1) and potassium phosphite (Table 1). Treatment with all three BABA compounds resulted in reduced decay formation at a concentration of $500 \mu \mathrm{g} / \mathrm{ml}$, providing 82 to $90 \%$ control of the disease. When applied at a concentration of $250 \mu \mathrm{g} / \mathrm{ml}$, BABA, $S$-BABA, and $R$-BABA provided 89,68 , and $81 \%$ inhibition, respectively (Fig. 1). At a concentration of $50 \mu \mathrm{g} / \mathrm{ml}$, only $S$ - and $R$-BABA provided significant inhibition, 41 and $49 \%$ inhibition, respectively (Fig. 1). Potassium phosphite completely inhibited decay development at a concentration of $500 \mu \mathrm{g} / \mathrm{ml}$ (Table 1). At a concentration of $50 \mu \mathrm{g} / \mathrm{ml}$, potassium phosphite significantly $(P<$ 0.05 ) inhibited decay development, providing $45 \%$ inhibition relative to the control (Table 1).

Postinoculation application of BABA, $S$ BABA, and potassium phosphite significantly inhibited decay formation in fruits at all times of application (Fig. 2). At $6 \mathrm{~h}$ postinoculation, potassium phosphite, BABA, and $S$-BABA provided 98,83 , and $86 \%$ inhibition, and at $48 \mathrm{~h}$, the compounds provided 68,68 , and $78 \%$ inhibition, respectively (Fig. 2).

In vitro assays. Conidial germination of the fungus was generally more sensitive to potassium phosphite than to BABA. The

Table 1. Effect of potassium phosphite on development of apple fruit decay caused by Alternaria alternata on detached apple fruits

\begin{tabular}{lcc}
\hline $\begin{array}{l}\text { Concentration } \\
(\boldsymbol{\mu g} / \mathbf{m l})\end{array}$ & $\begin{array}{c}\text { Decay } \\
\text { diameter }^{\mathrm{x}} \\
(\mathbf{m m})\end{array}$ & $\begin{array}{c}\text { Inhibition }^{\mathrm{y}} \\
(\boldsymbol{\%})\end{array}$ \\
\hline 0 & $20.2 \mathrm{a}^{\mathrm{z}}$ & $\ldots$ \\
50 & $11.2 \mathrm{~b}$ & 45.0 \\
500 & $0.0 \mathrm{c}$ & 100.0 \\
\hline
\end{tabular}

${ }^{\mathrm{w}}$ Each fruit was pricked with a pipet tip and inoculated at six sites with $15 \mu \mathrm{l}$ of an aqueous mixture of conidial suspension and potassium phosphite. Following inoculation, fruits were incubated in a moist chamber and held at $25^{\circ} \mathrm{C}$ for 10 days.

$x$ The mean diameter of decay at each inoculation site as measured 10 days after inoculation. Means are from six inoculation sites on each of three apples per treatment. These are combined results of two repeated experiments.

${ }^{\mathrm{y}}$ Inhibition is expressed as a percentage of the untreated control.

${ }^{\mathrm{z}}$ Means within columns followed by different letters are significantly $(P<0.05)$ different according to Waller-Duncan $k$-ratio $t$ test.
$\mathrm{EC}_{50}$ and $\mathrm{EC}_{90}$ values for in vitro inhibition of conidial germination were lowest for potassium phosphite (Table 2). For BABA compounds $\mathrm{EC}_{50}$ and $\mathrm{EC}_{90}$ values were higher and ranged between 620 to $>1,000$ $\mu \mathrm{g} / \mathrm{ml}$ (Table 2). In water, the average conidial germination of A. alternata at $20 \mathrm{~h}$ was $94 \%$.

Mycelial growth of $A$. alternata in vitro was more sensitive to potassium phosphite than to BABA (Table 2). Mycelial growth was not affected by BABA, $S$-BABA, and $R$-BABA $\left(\mathrm{EC}_{90}>1,000 \mu \mathrm{g} / \mathrm{ml}\right)$ (Table 2). In control plates, the average colony diameter of A. alternata after 6 days was 33 $\mathrm{mm}$.

Field experiment. Incidence of natural infection of fruits by A. alternata was relatively high, reaching $46 \%$ of the fruits on nontreated control trees (Table 3). Three foliar applications of difenoconazole, $\mathrm{BABA}$, or potassium phosphite reduced the number of percentage of fruits colonized with $A$. alternata by 78,40 , and $40 \%$, respectively, compared to nontreated trees as determined on PDA just prior to commercial harvest (10 September) (Table 3 ). These compounds also significantly reduced moldy-core incidence ( 0 to $6 \%$ infected fruits), as compared to 8.6 to $10 \%$ infected fruits in the nontreated control plots, as determined by visual estimation at both sampling dates (Table 3).

\section{DISCUSSION}

Moldy-core in apple fruits, incited predominantly by A. alternata, is an important disease in Israel and elsewhere. Fungicides applied in the field are not effective after the fungus has penetrated the host fruit. Therefore, compounds that perform by inducing resistance in the host could be attractive alternatives. In this study, we chose to evaluate BABA and related compounds, which were recently reported (6) to induce resistance against a variety of diseases, as well as potassium phosphite which is known for its dual mode of action on the pathogen and the host $(7,11)$.

The data indicate that BABA and phosphite perform via different mechanisms against moldy-core. BABA had no

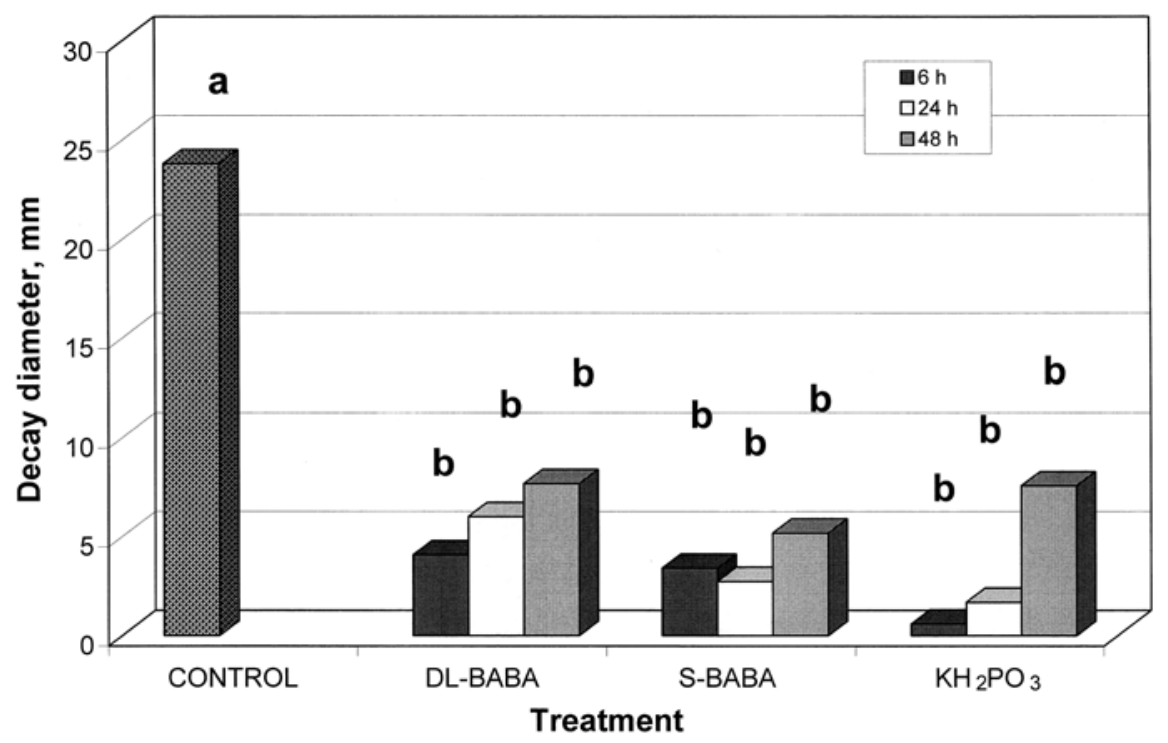

Fig. 2. Postinoculation activity of BABA and potassium phosphite on development of decay caused by Alternaria alternata on detached apple fruits. Six sites on each fruit were inoculated with $15 \mu \mathrm{l}$ of conidial suspension, and $0,6,24$, and $48 \mathrm{~h}$ after inoculation they were treated with $30 \mu \mathrm{l}$ of each compound at a concentration of $500 \mu \mathrm{g} / \mathrm{ml}$. Fruits were incubated in a moist chamber at $25^{\circ} \mathrm{C}$ for 10 days. The mean decay diameter produced in each inoculation site of each of three fruits per compound concentration is shown. Bars with different letters are significantly $(P<0.05)$ different according to Waller-Duncan $k$-ratio $t$ test.

Table 2. $\mathrm{EC}_{50}$ and $\mathrm{EC}_{90}$ values of $\mathrm{DL}-\beta$-aminobutyric acids (BABA) compounds and potassium phosphite for conidial germination and mycelial growth of Alternaria alternata in vitro ${ }^{\mathrm{z}}$

\begin{tabular}{llcc}
\hline Response variable & Compound & $\mathbf{E C}_{\mathbf{5 0}}(\boldsymbol{\mu g} / \mathbf{m l})$ & $\mathbf{E C}_{\mathbf{9 0}}(\boldsymbol{\mu g} / \mathbf{m l})$ \\
\hline Conidial germination & BABA & 620 & $>1,000$ \\
& S-BABA & $>1,000$ & $>1,000$ \\
& R-BABA & 641 & 998 \\
\multirow{3}{*}{ Mycelial growth } & Phosphite & 229 & 531 \\
& BABA & $>1,000$ & $>1,000$ \\
& S-BABA & $>1,000$ & $>1,000$ \\
& R-BABA & $>1,000$ & $>1,000$ \\
& Phosphite & 278 & 515
\end{tabular}

$\overline{{ }^{\mathrm{z}} \mathrm{EC}_{50} \text { and } \mathrm{EC}_{90} \text { values are the concentrations causing } 50 \text { and } 90 \% \text { inhibition, respectively, of conid- }}$ ial germination and mycelial growth in vitro. 
Table 3. The effects of field applications of difenoconazole, BABA, and potassium phosphite on control of moldy-core (Alternaria alternata) in apple fruit

\begin{tabular}{|c|c|c|c|}
\hline \multirow{2}{*}{$\begin{array}{l}\text { Treatment and } \\
\text { concentration }(\%)^{\mathrm{y}}\end{array}$} & \multicolumn{2}{|c|}{$\begin{array}{l}\text { Percentage of fruits infected } \\
\text { with moldy-core }\end{array}$} & \multirow{2}{*}{$\begin{array}{c}\text { Percentage of fruits } \\
\text { colonized with } A \text {. alternata } \\
10 \text { September }\end{array}$} \\
\hline & 25 July & 10 September & \\
\hline Difenoconazole, 0.02 & $4.3 \mathrm{~b}^{\mathrm{z}}$ & $5.0 \mathrm{~b}$ & $13.1 \mathrm{c}$ \\
\hline BABA, 0.2 & $2.9 \mathrm{~b}$ & $6.0 \mathrm{~b}$ & $28.3 \mathrm{~b}$ \\
\hline Potassium phosphite, 0.3 & $0.0 \mathrm{~b}$ & $4.0 \mathrm{~b}$ & $27.6 \mathrm{~b}$ \\
\hline Control nontreated & $8.6 \mathrm{a}$ & $10.0 \mathrm{a}$ & $45.9 \mathrm{a}$ \\
\hline
\end{tabular}

$\mathrm{x}$ Twenty fruits from each replicate were brought to the laboratory at the given dates and examined for the presence of moldy-core symptoms in mesoderm and colonization by A. alternata.

y Three foliar sprays of each compound were applied starting at 50\% bloom (1 April 2001). Additional applications were made on 5 April (full bloom) and 11 April 2001 (80 to 90\% petal fall). Nontreated trees served as controls.

${ }^{\mathrm{z}}$ Means within columns followed by different letters are significantly $(P<0.05)$ different according to Waller-Duncan $k$-ratio $t$ test.

effect on fungal growth in vitro, but phosphite inhibited mycelial growth. Moldycore control by phosphite may therefore involve mycelial growth inhibition. Similarly, phosphite was inhibitory to conidial germination in vitro, but BABA was not, again indicating a direct effect of phosphite on the pathogen. This confirms previous findings that BABA has no detectable antifungal activity in vitro (8). Unlike BABA, a concentration of $1 \mu \mathrm{g} / \mathrm{ml}$ of the new strobilurin, trifloxystrobin effectively inhibited conidial germination of A. alternata (M. Reuveni, unpublished data).

Previous reports showed that the racemate $\mathrm{dl}-\mathrm{BABA}$ and the $R$ enantiomer of $\mathrm{BABA}$ were effective in inducing resistance against various pathogens including nematodes, whereas the $S$ enantiomer was ineffective or only partially effective (6). Here we show, for the first time, that $S$-BABA was effective against a fungal disease, suggesting that apple fruit tissue, unlike tissues of e.g., tomato, tobacco, arabidopsis, and grape recognizes $S$-BABA and $R$-BABA. This might indicate that the putative receptor for BABA in apple tissue has the capability to bind both enantiomers whereas other tissues can bind to $R$-BABA only.

The mode of action of BABA in apple fruits against $A$. alternata is not known. Previous studies showed that BABA induces a variety of defense mechanisms, including production of phenolics, peroxides, PR-proteins, callose, lignin, and more, depending on the host-pathogen system (6). The reaction of apple tissue to BABA application warrants a special study. The fact that BABA was effective even when applied $48 \mathrm{~h}$ after inoculation indicates a rapid activation of defense. Postinfection activity of BABA was reported in grape against Plasmopara viticola (8), in tobacco against Peronospora tabacina (3), in tomato against Phytophthora infestans (4) and other pathosystems (6).
In addition to direct effects on spore germination and mycelial growth, the mode of action of phosphite may involve phytoalexin accumulation as reported in other pathosystems $(7,11)$. Whether phosphite enhances phytoalexins in apple fruit is not known. The postinfection activity of potassium phosphite, however, has already been shown against other fungal pathogens $(7,16,19)$. In apple, phosphites were reported to be active against Phytophthora cactorum (12), Dematophora necatrix, and Venturia inaequalis (13).

The present research shows that BABA and potassium phosphite effectively control moldy-core. They did so on detached apples artificially inoculated in the laboratory and in naturally infected trees. Three foliar applications of $\mathrm{BABA}$ and potassium phosphite, between the beginning of bloom and petal fall, reduced the number of infected fruits with moldy-core by 40 and $60 \%$, respectively, compared with nontreated control trees. A previous study showed that the beginning of bloom and full bloom were the most susceptible developmental stages for infection by the pathogen (17). BABA and phosphite were as effective as the standard fungicide difenoconazole in controlling the disease in the field. These data may encourage the use of BABA and/or phosphite as alternatives to difenoconazole for controlling moldy-core.

Control of plant diseases with plant activators may become another component of integrated disease management, enabling better control of plant disease with reduced rate applications of fungicides, or better control by using combinations with existing fungicides. Additionally, they may preserve the useful life of fungicides by extending the period before pathogens develop resistance to the fungicide (15).

\section{LITERATURE CITED}

1. Biggs, A. R., Ingle, M., and Solihati, W. D. 1993. Control of Alternaria infection of fruit of apple cultivar Nittany with calcium chloride and fungicides. Plant Dis. 77:976980.

2. Brown, E. A., and Hendrix, F. F. 1978. Effect of certain fungicides sprayed during apple bloom on fruit set and fruit rot. Plant Dis. Rep. 62:739-741.

3. Cohen, Y. 1994. 3-Aminobutyric acid induces systemic resistance against Peronospora tabacina. Physiol. Mol. Plant Pathol. 44:273288.

4. Cohen, Y. 1994. Local and systemic control of Phytophthora infestans in tomato plants by DL-3-amino-n-butanoic acids. Phytopathology 84:55-59.

5. Cohen, Y. 1996. Induced resistance against fungal diseases by aminobutyric acids. Pages 461-466 in: Modern Fungicides and Antifungal Compounds. H. Lyr, P. E. Russel, H. D. Sisler, eds, Intercept, Andover, UK.

6. Cohen, Y. 2002. $\beta$-aminobutyric acid induced resistance against plant pathogens. Plant Dis. 86:448-457.

7. Cohen, Y., and Coffey, M. D. 1986. Systemic fungicides and the control of Oomycetes. Annu. Rev. Phytopathol. 24:311-338.

8. Cohen, Y., Reuveni, M., and Baider, A. 1999. Local and systemic activity of BABA (DL-3Aminobutyric acid) against Plasmopara viticola in grapevines. Eur. J. Plant Pathol. 105:351-361.

9. Combrink, J. C., Kotze, J. M., and Visagie, T. S. 1985. Colonization of apples by fungi causing core rot. Hortic. Sci. 2:9-13.

10. Ellis, M. A., and Barrat, J. G. 1983. Colonization of delicious apple fruits by Alternaria spp. and effect of fungicide sprays on moldycore. Plant Dis. 67:150-152.

11. Guest, D. I., and Grant, B. R. 1991. The complex action of phosphonates as antifungal agents. Biol. Rev. 66:159-187.

12. Guest, D. I., Pegg, K. G., and Whiley, A. W. 1995. Control of Phytophthora diseases of tree crops using trunk-injected phosphonates. Hortic. Rev. 17:299-330.

13. Heaton, J. B., and Dullahide, S. R. 1990 Efficiency of phosphonic acid in other pathogen systems. Aust. Plant Pathol. 19:133-134.

14. Miller, P. M. 1959. Open calyx tubes as a factor contributing to carpel discoloration and decay of apples. Phytopathology 49:520-523.

15. Newton, A. C., Miller, S. K., Lyon, G. D., and Reglinski, T. 1997. Resistance elicitors as crop protectants. (Abstr.) Phytopathology 87 (Suppl):S69.

16. Reuveni, M. 1997. Post-infection applications of $\mathrm{K}_{3} \mathrm{PO}_{3}$, potassium phosphite and dimethomorph inhibit development of downy mildew caused by Plasmopara viticola on grapevines. J. Small Fruit Vitic. 5:27-38.

17. Reuveni, M., Sheglov, D., Sheglov, N., BenArie, R. and Prusky, D. 2002. Sensitivity of Red Delicious apple fruit at various phenologic stages to infection by Alternaria alternata and moldy-core control. Eur. J. Plant Pathol. 108:421-427.

18. Spotts, R. A. 1990. Moldy core and core rot. Pages 29-30 in: Compendium of Apple and Pear Diseases. A. L. Jones and H. S. Aldwinckle, eds. The American Phytopathological Society, St. Paul, MN

19. Wicks, T. J., Magarey, P. A., Wachtel, M. F., and Frensham, A. B. 1991. Effect of postinfection application of phosphorous (phosphonic) acid on the incidence and sporulation of Plasmopara viticola on grapevine. Plant Dis. 75:40-43. 